\title{
BERLINER ABENDBLÄTTER.
}

\section{BRIEF EINES JUNGEN DICHTERS AN EINEN JUNGEN MALER}

Uns Dichtern ist es unbegreiflich, wie ihr euch entschließen könnt, ihr lieben Maler, deren Kunst etwas so Unendliches ist, jahrelang zuzubringen mit dem Geschäft, die Werke eurer großen Meister zu kopieren. Die Lehrer, bei denen ihr in die Schule geht, sagt ihr, leiden nicht, daß ihr eure Einbildungen, ehe die Zeit gekommen ist, auf die Leinewand bringt; wären wir aber, wir Dichter, in eurem Fall gewesen, so meine ich, wir würden unsern Rücken lieber unendlichen Schlägen ausgesetzt haben, als diesem grausamen Verbot ein Genüge zu tun.

Denn die Aufgabe, Himmel und Erde! ist ja nicht, ein anderer, sondern ihr selbst zu sein, und euch selbst, euer Eigenstes und Innerstes, durch Umriß und Farben, zur Anschauung zu bringen! Wie mögt ihr euch nur in dem Maße verachten, daß ihr willigen könnt, ganz und gar auf Erden nicht vorhanden gewesen zu sein;

Aber ihr Leute, ihr bildet euch ein, ihr müßtet durch euren Meister, den Raphael oder Corregge, oder wen ihr euch sonst zum Vorbild gesetzt habt, hindurch; da ihr euch doch ganz und gar umkehren, mit dem Rücken gegen ihn stellen, und, in diametral entgegengesetzter Richtung, den Gipfel der Kunst, den ihr im Auge habt, auffinden und ersteigen könntet. - 